International Journal of Current Advanced Research

ISSN: O: 2319-6475, ISSN: P: 2319 - 6505, Impact Factor: SJIF: 5.995

Available Online at www.journalijcar.org

Volume 6; Issue 5; May 2017; Page No. 3812-3815

DOI: http://dx.doi.org/10.24327/ijcar.2017.3815.0373

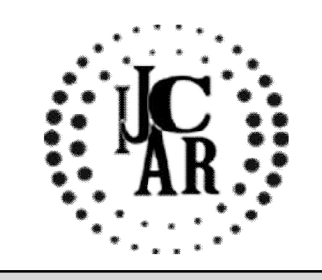

Research Article

\title{
RELATIONSHIP BETWEEN WEIGHT AND BLOOD PRESSURE IN HYPERTENSIVE PATIENTS
}

\author{
Elakkiya I and Preetha
}

Saveetha Dental College and Hospitals

\begin{tabular}{l}
\hline A R T I C L E I N F O \\
\hline Article History: \\
Received $19^{\text {th }}$ February, 2017 \\
Received in revised form $12^{\text {th }}$ March, 2017 \\
Accepted $5^{\text {th }}$ April, 2017 \\
Published online $28^{\text {th }}$ May, 2017 \\
\end{tabular}

Key words:

Weight And Blood Pressure, Hypertensive

Copyright $₫ 2017$ Elakkiya I and Preetha. This is an open access article distributed under the Creative Commons Attribution License, which permits unrestricted use, distribution, and reproduction in any medium, provided the original work is properly cited.

\section{INTRODUCTION}

Elderly population contributed to $7 \%$ of the total population in India in 2001 \& it will rise to $9 \%$ by 2016 , a majority of this population will be living in rural areas. According to an estimate they will constitute one third of the total population of the world of 2050 AD (Park, 2008). Life expectancy in India has increased from 37 years (1951) to 67 years (2011) due to overall socioeconomic and health care developments, so is the co-morbidity like overweight and obesity. Body mass index is positively and independently associated with morbidity and mortality from hypertension, cardiovascular disease, diabetes mellitus, and other chronic diseases. Not much data is available regarding the association between obesity and hypertension in the elderly. Few studies have shown a correlation between body mass index (BMI) and systolic and diastolic blood pressures in the elderly (Joshi, 2007). Hypertension has been reported in $40-48 \%$ geriatric patients in India. Hypertension is a threat to life at all ages and in both sexes. It is one of the leading cardiovascular disorder and an important risk factor for coronary artery disease, cerebrovascular diseases and cardiac failure in elderly subjects (Gupta, 2004). Unfortunately, studies in India regarding the correlation between blood pressure and BMI in elderly people are lacking. The knowledge of the effect of increased BMI especially obesity on hypertension is very important as it is a modifiable risk factor. Our aim of this study is to find out the association between body mass index and blood pressure in the elderly population.

\footnotetext{
*Corresponding author: Elakkiya I
}

Saveetha Dental College and Hospitals
The specific research questions for this study was that among cases aged 60 years or more a) does correlation exists between body mass index and systolic and diastolic blood pressure; b) do those who were in the highest group of BMI as compared to those within the lowest group, have a higher prevalence of hypertension.

Globally, high blood pressure (BP) is estimatedto cause 7.1 million deaths, about $13 \%$ of thetotal. About $62 \%$ of cerebrovascular disease and $49 \%$ of ischemic heart disease are attributable to suboptimal BP (systolic $4115 \mathrm{~mm} \mathrm{Hg}$ ). Overweight and obesity increase the risks of high BP, coronary heart disease, ischemic stroke, type IIdiabetes mellitus and certain cancers. Worldwide about $58 \%$ of diabetes mellitus and $21 \%$ ofischemic heart disease are attributable to BMI above $21 \mathrm{~kg} / \mathrm{m} 2.1$ Developing countries are increasingly faced with the double burden of hypertension and other cardiovascular diseases, along with infection and malnutrition. Hypertension places an excessive financial burden on populations and health systems, consuming scarce resources. 4 Population-based preventive approaches are, thus, central for the management of elevated BP in developing countries, where clinic-based care for complications is nota feasible option (Kamal et al., 1997; Huang et al., 2007; Amador et al., 2006). Body mass index (BMI) is positively and independently associated with morbidity and mortality from hypertension, cardiovascular disease, type IIdiabetes mellitus and other chronic diseases.8 In Caucasian populations, a strong association has-been depicted between BMI and mortality (Gupta, 1995). A similar association has also been demonstrated among Asian populations. The relationship between $\mathrm{BMI}$ and $\mathrm{BP}$ has long been the subject of 
epidemiological research (Amador et al., 2007; Anil Kumar et al., 2008)

\section{METHODS}

The present study was conducted at three demographic surveillance sites (DSS) in Vellore, Arcot and Kalavai. The study was conducted in DSS in each of the three places. The DSS are composed of population cohorts, including urban and rural residents, where routine registration of vital events takes place. The DSS provided the sampling frames for data collection as well as background socioeconomic and demographic data. The population cohorts maintained by the DSS provide opportunities for future follow-up. The three DSS and the sampling method will be described in detail elsewhere.

\section{Study Procedures}

\section{Primary study variables and their collection:}

All anthropometric measurements like weight and height was performed according to WHO guide lines.[5] Weight was measured with bare foot using standardized weighing machine for all patients. Height was measured with barefoot and BMI was calculated. Blood pressure was recorded in the sitting position after 5minutes of rest using standard sphygmomanometer.

\section{Derived variables and their calculation}

Hypertension was diagnosed when systolic BP $>140 \mathrm{~mm} \mathrm{Hg}$ and/or diastolic $\mathrm{BP}>90 \mathrm{~mm} \mathrm{Hg}$ or a known hypertensive patient. BMI (weight in $\mathrm{Kg}$ )/(height in meters2) was calculated and divided in four groups like group I $(<20)$, group II (20.1- 22.5), group III (22.6-25), and group IV $(>$ 25.1).

\section{Statistical Analysis}

The patients were divided into four groups based on theirBMI group I ( $<20)$, group II (20.1- 22.5), group III (22.6- 25), and group IV $(>25.1)$. The mean systolic and diastolic blood pressure for both the male and female categories of patients was compared in the three categories of patients with students t-test. The mean blood pressure recordings between both the genders was also analyzed using students t-test. The software used for statistical analysis was strata version 11.

\section{RESULTS}

The present study, focusing on BMI and BP, have a crosssectional descriptive design, allowing internal comparisons across the three sites, and between the major sociodemographic groups, such as males and females, and urban and rural residents. Adults in the age group 25-64 years will be randomly selected using the DSS database in each place. Pregnancy (in women) and any gross physical abnormality will be the only exclusion criteria against the physical measurements. Sample size will be calculated using the 'formula for single population proportion'. The minimum sample size (250) will be determined for the smallest unit or strata in the study, that is, for each 10-year age interval in each sex and residence.

Altogether, 100 patients more than 60 years attending geriatric camp for general check-up were included in the study. Among them $80 \%$ were male, their mean age was 67.73 \pm 6.11 in male and $66.75 \pm 5.83$ in female. Mean BMI were $19.61 \pm 3.84 \mathrm{~kg} / \mathrm{m} 2$. Baseline comparison of characteristics of study subjects is shown in Table 1 . More cases $(n=57)$ were in BMI less than 20. Body mass quintile with different variable like age, sex, BMI, blood pressures, and smoking are shown in Table 2. Blood pressure and BMI in 5years age group are shown in table 3 . The blood pressures were found to increase progressively with the increase in BMI in both sexes. There was a statistically significant increase in thesystolic blood pressure $\mathrm{R}$ value $0.2214, \mathrm{p}<0.05$ as wellas diastolic blood pressure $\mathrm{R}$ value $0.2967, \mathrm{p}<0.05$. There were also statistically significant relation betweensmokers and blood pressures shown in Table 4.

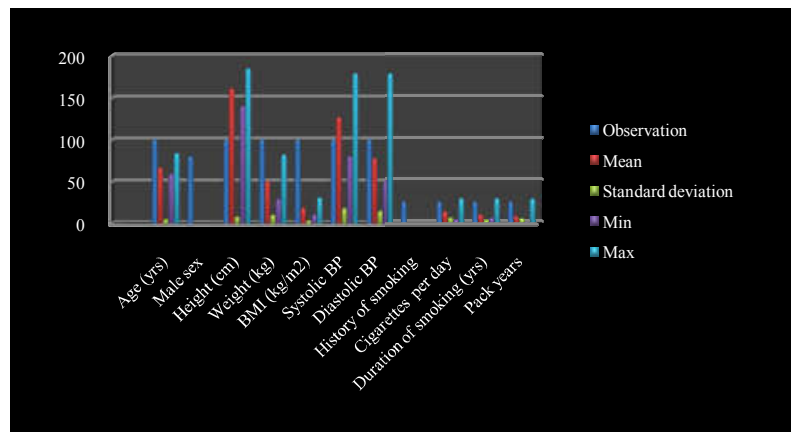

Fig 1 Baseline characteristics of patients

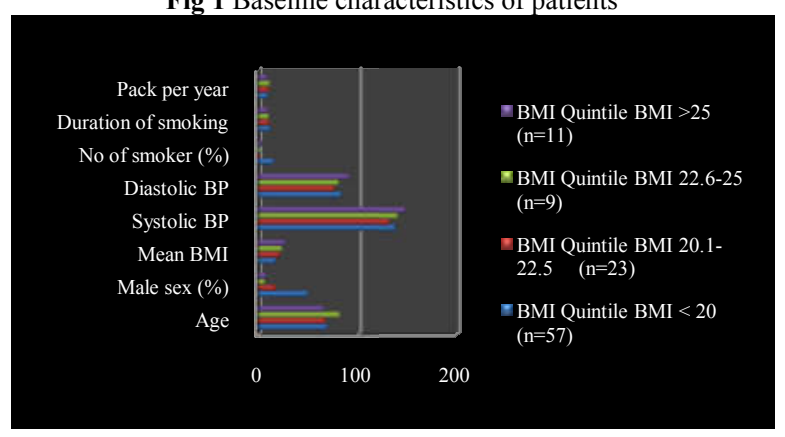

Fig 2 Body mass quintile with different variable

Table 1 Baseline characteristics of patients

\begin{tabular}{cccccc}
\hline Variable & $\begin{array}{c}\text { Observation } \\
\text { \% }\end{array}$ & Mean & $\begin{array}{c}\text { Standard } \\
\text { deviation }\end{array}$ & Min & Max \\
\hline Age (yrs) & 100 & 66.72 & 5.10 & 59 & 84 \\
Male sex & 80 & & & & \\
Height (cm) & 100 & 160.92 & 7.90 & 140 & 185 \\
Weight (kg) & 100 & 50.52 & 10.30 & 29 & 82 \\
BMI (kg/m2) & 100 & 18.61 & 3.50 & 10.38 & 30.80 \\
Systolic BP & 100 & 126.8 & 18.30 & 80 & 179 \\
Diastolic BP & 100 & 77.8 & 14.90 & 50 & 179 \\
History of smoking & 25 & & & & \\
Cigarettes per day & 25 & 13.92 & 6.60 & 3.9 & 29 \\
Duration of smoking (yrs) & 25 & 10.08 & 3.50 & 5.9 & 29 \\
Pack years & 25 & 8.312 & 5.27 & 1.1 & 28.6 \\
\hline
\end{tabular}


Table 2 Body mass quintile with different variable

\begin{tabular}{ccccc}
\hline & \multicolumn{4}{c}{ BMI Quintile } \\
\hline Variable & $\begin{array}{c}\text { BMI }<\mathbf{2 0} \\
(\mathbf{n = 5 7 )}\end{array}$ & $\begin{array}{c}\text { BMI 20.1-22.5 } \\
(\mathbf{n = 2 3})\end{array}$ & $\begin{array}{c}\text { BMI 22.6-25 } \\
(\mathbf{n = 9 )}\end{array}$ & $\begin{array}{c}\text { BMI > 25 } \\
(\mathbf{n = 1 1})\end{array}$ \\
\hline Age & $68.53+3.12$ & $66.83+6.90$ & $81+7.44$ & $65+1.14$ \\
Male sex (\%) & $49(85.9)$ & $17(73.9)$ & $6(66.6)$ & $8(72.7)$ \\
Mean BMI & $16.98+0.54$ & $21.16+0.32$ & $23.4+0.60$ & $26.88+1.16$ \\
Systolic BP & $137.73+11.19$ & $131.33+22.78$ & $140+20.12$ & $148+11.45$ \\
Diastolic BP & $82.53+6.25$ & $75.66+8.02$ & $80+6.34$ & $91.33+18.52$ \\
No of smoker (\%) & $15(26.3)$ & $6(26.08)$ & $1(11.1 \%)$ & $3(27 \%)$ \\
Duration of smoking & $11.66+2.02$ & $10.66+3.94$ & $10+3.78$ & $9.33+1.32$ \\
Pack per year & $9.23+2.99$ & $9.73+5.33$ & $11+2.22$ & $8.3+7.44$ \\
\hline
\end{tabular}

Table 3 Mean BMI, SBP and DBP across 5 years age groups

\begin{tabular}{ccccc}
\hline \multicolumn{5}{c}{ Age Group } \\
\hline Variable & $60-65$ & $66-70$ & $71-75$ & $>76$ \\
& $(\mathrm{n}=50)$ & $(\mathrm{n}=23)$ & $(\mathrm{n}=15)$ & $(\mathrm{n}=12)$ \\
Mean BMI & $19.66+0.94$ & $21.10+1.96$ & $18.42+1.70$ & $17.98+1.80$ \\
Mean SBP & $126.2+5.44$ & $129.21+8.94$ & $127.73+8.60$ & $131.83+9.90$ \\
Mean DBP & $79.88+5.04$ & $81.21+6.04$ & $75.6+7.70$ & $73.66+5.20$ \\
\hline
\end{tabular}

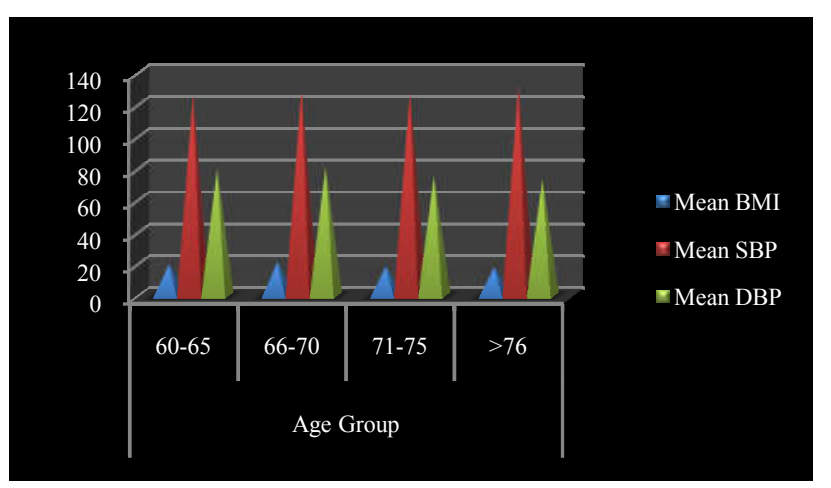

Fig 3 Mean BMI, SBP and DBP across 5 years age groups

Table 4 Correlation of BMI, Number duration of smoking and pack years with systolic and diastolic blood pressure

\begin{tabular}{ccccc}
\hline \multirow{2}{*}{ Variable } & \multicolumn{2}{c}{ Systolic blood pressure } & \multicolumn{2}{c}{$\begin{array}{c}\text { Diastolic blood } \\
\text { pressure }\end{array}$} \\
\cline { 2 - 5 } & R value & P value & R value & P value \\
\hline BMI & 0.2213 & $<0.05$ & 0.2967 & $<0.05$ \\
Cigarette smoking per & $0.6225^{*}$ & $<0.05$ & $0.4076^{*}$ & $<0.05$ \\
day & $0.6430^{*}$ & $<0.05$ & 0.2913 & $>0.05$ \\
Duration of smoking & $0.6441^{*}$ & $<0.05$ & 0.3017 & $>0.05$ \\
\hline Pack years & & &
\end{tabular}

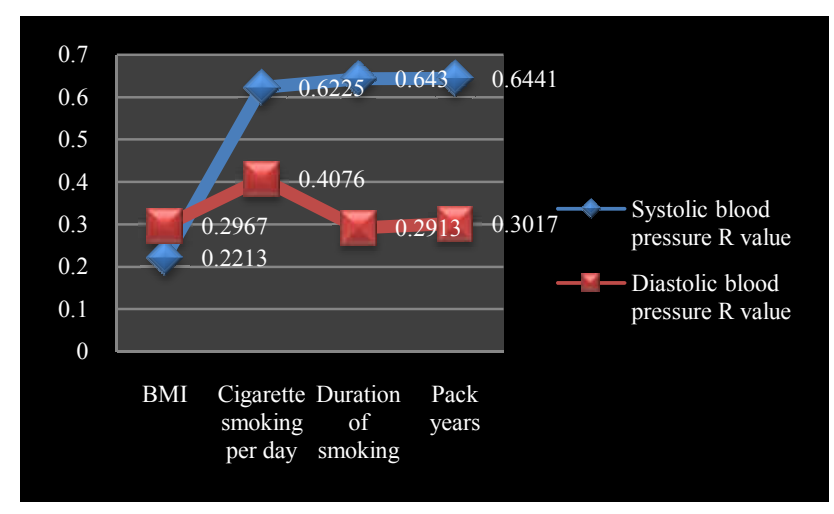

Fig 4 Correlation of BMI, Number duration of smoking and pack years with systolic and diastolic blood pressure

\section{DISCUSSION}

This study showed that BMI is significantly and independently associated with both SBP and DBP in elderly in rural teaching hospital.
Several studies revealed the close relationship between BMI and systolic and diastolic blood pressures in elderly.option (Kamal et al., 1997; Huang et al., 2007; Amador et al., 2006). Few study have shown relation between BMI and blood pressure was stronger in females than males.[8] However, in our study, the influence of sex on hypertension was statistically not significant for both systolic and diastolic blood pressure $(\mathrm{p}>0.05)$.

Hypertension is one of the most common chronic conditions seen in the elderly population. If control of weight in the elderly helps in reduction of blood pressure, active lifestyle and a healthy diet are cost-effective measures in improving the quality of life in the elderly. When the mean systolic and diastolic blood pressures among different BMI categories were evaluated, it was found that mean systolic and diastolic blood pressure increased with increasing BMI from lowest BMI to the highest BMI category. Both systolic and diastolic BP increased with increase in BMI level. Positive associations between BMI and BP have also been reported in other Indian populations.option (Kamal et al., 1997; Huang et al., 2007; Amador et al., 2006).

Few studies have emphasized the synergism of smoking with hypertension. The pathogenetic mechanism by which smoking contributes to this is endothelial dysfunction. Nicotine damages endothelium and tobacco smoke increases smooth muscle cell proliferation and adhesion, leading to atherosclerosis and blood pressure.option (Kamal et al., 1997; Huanget al., 2007; Amador et al., 2006). The data obtained from our study for the association of BMI and blood pressure is limited. Further studies in a larger scale are warranted to establish the correlation between them.

\section{CONCLUSION}

The association between BMI and both systolic and diastolic pressures remained highly statistically significant in these analyses. These results show that as BMI increases blood pressure rises even in old age and suggest that it may be possible to modify rates of hypertension by changes in body weight.

\section{References}

Amador LF, AL Snih S, Markides KS, GoodwinJSA. 2006. Body mass index and change in blood pressureover a 7-year period in older Mexican Americans.

Anil Kumar T, Sudhir U, Gita Srinivasan, Punith K.Association of Body Mass Index with BloodPressure in the Elderly. JIACM., 2008; 9(4): 274-6

Arakaki S, Maeshiro T, Hokama A, Hoshino K, Maruwaka S, Higashiarakawa M(1), Parrott G(1), Hirata T(1), Kinjo K(1), Fujita J(1). Factors associated with visceral 
fat accumulation in the general population in Okinawa, Japan. World J Gastrointest PharmacolTher. 2016 May 6;7(2):261-7. doi: 10.4292/wjgpt.v7.i2.261.

Gupta,R. S. Gupta, V. P. Gupta, and H. Prakash,"Prevalence and determinants of hypertension in theurban population of Jaipur in western India," Journal of Hypertension, 1995; 13(10): 1193-1200.

Gupta. R Trends in hypertension epidemiology in India. Journal of Human Hypertension 2004; 18.WHO Expert Committee. Physical Status: the useand interpretation of anthropometry. WHOTechnical Report Series., 1995; 854: 424-38.

Huang XB, Hu R, Liu JL et al. Relationship betweenbody mass index, waist circumference and bloodpressure among 5,246 residents in Chongqing area. Zhonghua Xin Xue Guan Bing Za Zhi., 2007; 35(7):655-8.
Joshi, V. J. Lim, M. Nandkumar. Prevalence andRisk Factors of Undetected Elevated Blood Pressurein an Elderly Southeast Asian Population. Asia Pac JPublic Health., 2007; 19(2): 3-9.

Kamal H, Masaki J, David Curb et al. Association ofBody Mass Index with Blood Pressure in ElderlyJapanese American Men. Hypertension., 1997; 29:673-7.

Kozono A, Isami K, Shiota K, Tsumagari K, Nagano M, Inoue D, Adachi R, Hiraki Y, Nakagawa Y, Kamimura H, Yamamichi K. Relationship of Prescribed Drugs with the Risk of Fall in Inpatients. Yakugaku Zasshi. 2016; 136(5):769-76. doi: 10.1248/yakushi.15-00245.

Park. K. Demography and epidemiology. Text Bookof Preventive and Social Medicine 2008: 21st Edn, M/s BanarsidasBhanot Publishers, Jabalpur, India.,2008; 458.

\section{How to cite this article:}

Elakkiya I and Preetha (2017) ' Relationship Between Weight And Blood Pressure In Hypertensive Patients', International Journal of Current Advanced Research, 06(05), pp. 3812-3815.

DOI: http://dx.doi.org/10.24327/ijcar.2017.3815.0373 